\title{
Effect of Music therapy on Labor Pain among Women in Active Labor Admitted in Tertiary Care Hospital Kochi
}

\author{
Tintu Xavier *1, Lekha Viswanath ${ }^{2}$.
}

${ }^{* 1}$ 2nd year M Sc nursing, Obstetrics \& Gynaecological Nursing , Amrita College of Nursing, Amrita Viswa Vidyapeetham, Kochi, India.

${ }^{2}$ Associate Professor , Obstetrics \& Gynaecological Nursing , Amrita College of Nursing, Amrita College of Nursing, Amrita Viswa Vidyapeetham, Kochi, India.

\section{ABSTRACT}

Introduction: The pain associated with birth of baby is perceived severe, unpleasant and traumatizing by the women. It is an individualized phenomenon with both sensory and emotional elements. Labour pain arises from distension of the lower uterine segment and cervical dilatation. Anxiety and pain are closely interrelated with each other. Providing comfort to the women in labour is still a challenge for the nurse midwives. The present study intends to assess the effect of music therapy on labour pain and anxiety among women in first stage of labour in a tertiary care hospital kochi, India.

Materials and M ethods: Quasi-experimental pretest post test control group design was used for the study. The sample consists of 40 women in active stage of labour, with cervical dilatation of $4-7 \mathrm{~cm}$. First 20 women were allotted to control group and next 20 to experimental group in order to avoid contamination. Background information was collected using semi structured interview and record review. Visual analogue scale was used to measure pain and anxiety. After the pretest measurement of pain and anxiety the women in the experimental group were then given music therapy for 30 minutes using headset. The posttest was done at the $30^{\text {th }}$ and $60^{\text {th }}$ minute after the pretest.

Results: The mean post test pain score of the experimental group (7.9) was

Significantly lower than the posttest score of the control group at $30^{\text {th }}$ minute $(5.75+/-0.44$ vs $8.55+/-0.51, p<$ $0.001)$ and $60^{\text {th }}$ minute $(7.9+/-0.45$ vs $8.7+/-0.47, p<0.001)$. No difference was observed in uterine contraction between the groups. The mean anxiety score of the experimental group was lower than the control group $(p<0.001)$

Conclusion: The result of the present study concludes that music therapy in effective in reducing the pain and anxiety of women in labour without affecting the uterine contractions. So music can be used as a non pharmacological pain management measure for providing comfort during labour.

KEY WORDS: M usic Therapy, Labour Pain and anxiety, Non-pharmacologic pain management.

Addressfor correspondence: M s. Tintu Xavier, 2nd year M Sc nursing , Obstetrics \& Gynaecological Nursing, Amrita College of Nursing, Amrita Viswa Vidyapeetham, Kochi-41, Kerala, India.

E-Mail: tintujoseph@ymail.com

\begin{tabular}{|c|c|c|}
\hline \multicolumn{3}{|c|}{ Online Access and Article Informtaion } \\
\hline \multirow{2}{*}{$\begin{array}{c}\text { Quick Response code } \\
\text { Dol: } 10.16965 \text { /ijims.2016.145 }\end{array}$} & \multicolumn{2}{|c|}{$\begin{array}{l}\text { International Journal of Integrative Medical Sciences } \\
\text { www.imedsciences.com }\end{array}$} \\
\hline & $\begin{array}{l}\text { Received: 01-08-2016 } \\
\text { Reviewed: 02-08-2016 }\end{array}$ & $\begin{array}{l}\text { Accepted: 22-08-2016 } \\
\text { Published: 30-11-2016 }\end{array}$ \\
\hline Source of Funding: Self & \multicolumn{2}{|c|}{ Conflicts of interest: None } \\
\hline
\end{tabular}

\section{BACKGROUND}

Labour is a unique experience associated with a wonderful and meaningful life event, the birth of the baby at the same time unpleasurable because of the pain associated with it. The experience of labor pain is a complex, subjective and multidimensional response to sensory stimuli generated during childbirth. It is caused 
by contractions of the uterine muscles and by pressure on the cervix. It can be felt as strong cramping in the abdomen, groin, and back, achy feeling and pain in sides or thighs. It is distinct sensation, therefore, can be differentiated from other sensations, there by affecting the individuals perception of pain [1].

For women, labor pain is severe, unpleasant and traumatizing feeling. It is also an individualized phenomenon with both sensory and emotional elements [2]. It arises from dilatation of cervix and the lower uterine segment. In the first stage of labor the lower uterine segment and the cervix of the uterus get gradually stretched causing visceral pain. As the first stage of labor progresses the intensity of pain grows. The average length of the first stage of labor is 12 to 14 hours and the woman has to experience pain for a prolonged period of time. The nerves at the level from T10 to L1 transmit the labor pain during this stage, so most pain is felt in the lower abdomen. Apart from this, Women feel pain in the back, buttocks, hips and the actual wall of the abdomen; however, back pain is the most common location of referred pain and it is found that $74 \%$ women experienced back pain in labor[3]. Although labour is a pleasurable experience, it is perceived distressing many of the women, because of the pain associated with, which is experienced for a long time with increasing intensity. If the pain during labour is controlled, labour becomes a more satisfying experience for the women.

A randomized controlled trial was conducted by Phumdong and Good (2003) [4] to examine the effect of music therapy on sensation and distress of labour pain in 110 primiparous women during the active phase of labour in Thailand. In the experiment, soft music had been played for 3 hours to women since the active phase of labour. Dual visual analogue scale was used to measure sensation and distress of pain before starting the study and at 3hourly post-tests. One-way repeated measures analysis of covariance indicated that those in music group had significantly less sensation and distress of pain than those in control group. In this study it is revealed that music have reduced substantially severe pain across 3hours of labour and delayed the increase of affective pain for 1 hour.
Leodoro J. Labrague, Rheajane A. Rosales, Gilbey L. Rosales, Gerald B. Fiel [5] were conducted a study on the effects of soothing music on labor pain among Filipino mothers. It was a quasi-experimental design with random assignment was utilized in this study. Fifty subjects were taken by dividing them into either music $(n=25)$ or non-music group $(n=25)$. Ten point visual analogue scale (VAS) was used to assess the participants' levels of pain and the behavioral rating scale (BRS) for pain at two time period. Both group were given the usual standard routine of care, however, music group was exposed to music therapy for 30 minute. It is seen that those in the music group had statistically significant reduction in reported pain levels compared to those in the non-music group [VAS $(t=7.317, p<0.05)$ and BRS $(t=8.128$, $\mathrm{p} \bigotimes$.050)].

The above studies show that music therapy can be used as non-pharmacologic pain management method during delivery. As it is a non-pharmacological intervention it does not cause side-effects on neonate. It can be easily carried out by the midwifes or by the mothers during labour itself. Furthermore, use of music during labour is cost effective and non-invasive method of pain management. Therefore it is imperative to conduct more scientific studies to fathom the effectiveness of music therapy as pain management tool to ensure best fetal outcomes. The objective of the present study is to investigate the effect of music therapy on the level of pain among women in active stage of labour. It also evaluates the effect of music on the level of anxiety.

Objectives of present study are Compare the level of labour pain between experimental and control group, Compare the level of anxiety between experimental and control group and assess the opinion regarding music therapy during labour among mothers in experimental group.

\section{MATERIALS AND METHODS}

The research design selected for the present study is pretest-posttest control group design. The study was conducted in the labour room of Amrita Institute of Medical Sciences and Research Center Kochi. Period of data collection 
was from February-march 2016. When a woman is admitted to labour room with pain, their eligibility to participate in the study was determined by evaluating the sampling criteria, which include cervical dilatation $4-7 \mathrm{~cm}, 37-42$ weeks of gestation, without any complication and received no pain medications in the last two hours. Eligible women were approach by the investigator and explanation regarding the study was given. All the willing women who met the criteria were included for the study. First 20 women were recruited for the experimental group and another 20 women for control group to avoid contamination.

Data collection was started after obtaining ethical clearance from the institutional of ethical committee. Participation was based on willingness and informed consent was obtained from all the women participated in the study.

The background demographic and clinical data was obtained using semi- structured interview and record review. Ten point visual analogue scale was used to assess the level pain and anxiety. Uterine contractions were assessed for 10 minutes by placing the hand over the fundal area above the umbilicus. The duration of each contraction is noted and level of pain felt during each contraction is measured using visual analogue scale soon after each contraction. The average score of pain and duration of contraction of three consecutive uterine contractions are taken as one measurement in pretest and posttests. The level of anxiety was measured after the assessment of pain.

The women in the experimental group were then given music therapy for 30 minutes using headset after the pretest. M usic therapy is the independent variable of the study. It used combination of songs based on selected ragas like Kapi, Hintholam, M ayamalavagoularaga, yamunakalyani, Neelambari and chalanatta. Songs were played randomly from a pool of 35 songs for 30 minutes.

The posttest assessment of pain was assessed at the $30^{\text {th }}$ minute (soon after 30 minutes of music therapy) and $60^{\text {th }}$ minute of the pretest..Posttest of anxiety was assessed at the $30^{\text {th }}$ minute. The data was analyzed using appropriate descriptive and inferential statistics.

\section{RESULTS}

Fig. 1: Bar graph showing percentage distribution of pain among group.

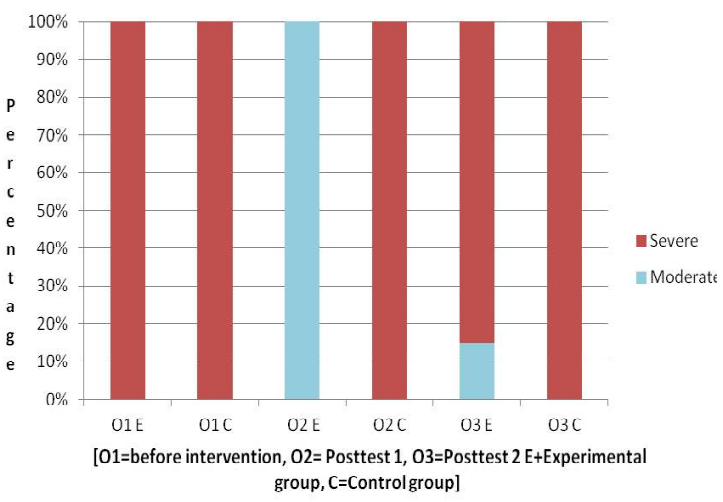

Table 1: Comparison between pretest and posttest of pain scores in experimental and control group.

\begin{tabular}{|c|c|c|c|c|c|c|}
\hline Pain & group & $\mathbf{N}$ & Mean & $\begin{array}{c}\text { Std. } \\
\text { Deviation }\end{array}$ & t Value & p Value \\
\hline \multirow{2}{*}{01} & $\begin{array}{l}\text { eperimental } \\
\text { group }\end{array}$ & 20 & 8.9 & 0.45 & \multirow[t]{2}{*}{1.994} & \multirow[t]{2}{*}{0.053} \\
\hline & control group & 20 & 8.6 & 0.5 & & \\
\hline \multirow[t]{2}{*}{02} & $\begin{array}{l}\text { eperimental } \\
\text { group }\end{array}$ & 20 & 5.75 & 0.44 & \multirow[t]{2}{*}{-18.505} & \multirow[t]{2}{*}{$\varangle 0.001$} \\
\hline & control group & 20 & 8.55 & 0.51 & & \\
\hline \multirow[t]{2}{*}{03} & $\begin{array}{c}\text { eperimental } \\
\text { group }\end{array}$ & 20 & 7.9 & 0.45 & \multirow[t]{2}{*}{-5.514} & \multirow[t]{2}{*}{$\varangle 0.001$} \\
\hline & control group & 20 & 8.7 & 0.47 & & \\
\hline
\end{tabular}

[01=before intervention, $02=$ Posttest $1,03=$ Posttest 2]

Demographic data: The age group of the participants was from $18-40$ years, $60 \%$ of the experimental group and $50 \%$ of the control group were of 26-35 years. Majority of both groups were graduates/ post graduates. All the women of both group had moderate level of physical activity. About $60 \%$ of the experimental group and $45 \%$ of the control group were multi gravid.

Level of pain during active labour: In the pretest all the women in both groups had severe pain. In posttest 1 all the women in the control group had severe pain where as in the experimental group all of them had moderate pain. In posttest $285 \%$ of the women had severe pain and in control group all of them continue to have severe pain. (Figure 1)

The mean pain score of the experimental group and control group was $8.9+/-0.45$ and $8.6+/-$ 0.50 respectively in the pretest which was not different significantly. In post test 1 the mean pain score of the experimental group reduced to $5.75+/-0.44$ and it became $7.9+/-0.45$ in posttest 2. Where as in control group the mean pain score was $8.55+/-0.51$ and $8.7+/-0.47$ respectively in posttest 1 and 2 . In posttest $1 \& 2$ 
the mean pain score of the experimental group was significantly lower than control group at $\mathrm{p} \varangle 0.001$ (Table 1).

Level of Anxiety: The mean anxiety score of experimental group in pretest observation is 8.55 which then decreased to 5.55 in the posttest. The mean anxiety score of the control group remains the same. The anxiety score of both the groups were not significantly in the pretest. In the posttest the mean anxiety score of experimental group was significanly lower than the control group at $p \varangle 0.001$ (table 2)

Table 2: Comparison of anxiety scores among experimental and control group.

\begin{tabular}{|c|c|c|c|c|c|}
\hline Groups & $\mathbf{N}$ & Mean & SD & $\mathbf{p}$ value & t value \\
\hline Pretest & & & & & \\
\hline Experimental & 20 & 8.45 & 0.51 & \multirow{2}{*}{0.539} & \multirow{2}{*}{0.62} \\
\hline Control & 20 & 8.55 & 0.51 & & \\
\hline Posttest & & & & & \\
\hline Experimental & 20 & 5.55 & 0.51 & \multirow{2}{*}{$\diamond .001$} & \multirow{2}{*}{18.586} \\
\hline Control & 20 & 8.55 & 0.51 & & \\
\hline
\end{tabular}

Duration of uterine contraction: There was significant difference in the mean duration of uterine contraction between the experimental and control group in the pretest as well as posttest 1 and 2 .

Description of mothers' experience with music therapy during labour: All women were comfortable with music therapy given in labour. All the women felt music therapy is useful in reducing their pain, tension and anxiety. All women reported that they were comfortable during music therapy. All of them expressed that music therapy gives a totally new experience.

\section{DISCUSSION}

Music therapy is a non pharmacological intervention which has been used widely to promote comfort as well as relaxation. The present study investigates the effectiveness of music therapy in reducing pain perception during active labour. M usic therapy, which included songs based on selected ragas was given to the women in experimental group for 30 minutes. The result of the study suggests that the music was effective in reducing pain and anxiety during labour. There was no difference in duration of uterine contraction in music therapy.

An experimental study was conducted on the effect of soothing music on labor pain among fifty Filipino mothers. Findings revealed that the mean post-test scores of the experimental group was significantly lower than the control group with $t=7.317$ significant at 0.05 level [5]. In this present study there was reduction in the pain score in experimental group after music therapy from 8.9 in pretest observation to 5.75 and 7.9 in pretest- 1 and pretest- 2 respectively. The difference in the level oflabour pain was significant at 0.001 level.

Another study was conducted on the effect of music therapy on pain and anxiety among primigravid women during first stage of labour. The results of the study revealed that $100 \%$ of the control group experienced severe pain at 8$9 \mathrm{~cm}$ cervical dilation and $86.67 \%$ experienced severe anxiety at $5-6 \mathrm{~cm}$ cervical dilation. Among experimental group $33.33 \%$ experienced moderate pain at $8-9 \mathrm{~cm}$ cervical dilation and $70 \%$ experienced moderate anxiety at $5-6 \mathrm{~cm}$ cervical dilation [6]. In the present study all the women in both groups had severe pain in the pretest. In posttest 1 all the women in the experimental group reported moderate pain where as in control group all of them had severe pain. The mean anxiety score of experimental group was significantly lower than the control group in the posttest. Other experimental studies also shows that music therapy reduced pain and anxiety during labour [7].

\section{CONCLUSION}

As music therapy is found to reduce pain and anxiety during labour, it can be used as a non pharmacological intervention for labour pain. It does not need much training and can be used with ease. Music therapy is a cost effective intervention to reduce pain during labour.

\section{REFERENCES}

[1]. Lowdermilk,Perry, Maternity nursing $7^{\text {th }}$ edition, M issouri:mosby publishers,2004;page no.338

[2]. Myles,Text book for midwives, $7^{\text {th }}$ edition, Elsever publishers. 2014; page no.349

[3]. http://www.allaboutepidural.com/main-content/ nature-of-labor-pain-why-it-hurts-and-what-toexpect

[4]. Phumdong, S,\&Good,M .(2003). Music reduces sensation and distress of labour pain. Pain management nursing 2003;4;(2):54-61. Abstract from:PM ID: 12836149(pub med index for M EDLINE 
[5]. Leodoro J. Labrague, Rheajane A. Rosales, Gilbey L. Rosales, Gerald B. Fie, Effects of soothing music on labor pain among Filipino mothers, Peer-reviewed and Open Access Journal for the Clinical Nursing Specialists. 2013;1(1): I.

[6]. Anjaly K.S, Sulochana kumar, Dr.Sreedevi, Effect of music therapy on pain and anxiety among primigravid women during first stage of labour, The official journal of Trained Nurses Association of India,kerala, 2015;5(1):16-22.
[7]. Nayak, Sharada Rastogi, Om Kumari Kathuria , Effectiveness of music therapy on anxiety level, and pain perception in primipara mothers during first stage of labor in selected hospitals of Odisha, IOSR Journal of Nursing and Health Science (IOSR-JNHS) e-ISSN: 2320-1959.p- ISSN: 2320-1940 2014; $3(2): 07-14$.

\section{How to cite this article:}

Tintu Xavier, Lekha Viswanath. Effect of M usic therapy on Labor Pain among Women in Active Labor Admitted in Tertiary Care Hospital Kochi. Int J Intg Med Sci 2016;3(11):444-448. DOI: 10.16965/ijims.2016.145 